\title{
SINERGIA
}

REVISTA DO INSTITUTO DE CIÊNCIAS ECONÔMICAS, ADMINISTRATIVAS E CONTÁBEIS (ICEAC)

\section{ANÁLISE DO PERFIL DOS EGRESSOS DO PROGRAMA DE PÓS-GRADUAÇÃO CONTÁBIL: UM ESTUDO NA FEARP/USP}

\author{
CLÁUDIO DE SOUZA MIRANDA \\ JOÃO PAULO RESENDE DE LIMA* \\ ADRIANA MARIA PROCÓPIO DE ARAÚJO*
}

\section{RESUMO}

A pós-graduação em contabilidade no Brasil teve seu início em 1970 e, seguindo tendências mundiais para garantir e aumentar a qualidade dos programas, iniciou-se, na década de 1990, o processo de avaliação externa. O modelo aplicado pela Coordenação de Aperfeiçoamento de Pessoal de Nível Superior (CAPES) é o resultado de um processo de aprimoramento de qualidade dos programas. Além da avaliação externa realizada pela CAPES, pode-se avaliar um programa internamente pelo acompanhando da trajetória de seu egresso e pela percepção deste sobre sua formação. O estudo teve como objetivo analisar a percepção do egresso do Programa de Pós-Graduação em Controladoria e Contabilidade (PPGCC), da Faculdade de Economia, Administração e Contabilidade de Ribeirão Preto (FEARP-USP), a respeito do curso e da sua experiência como pós-graduado. Foi realizada uma websurvey com 43 egressos, o que representou $46,2 \%$ do total até o ano de 2016. Os resultados apontaram que $58,1 \%$ dos titulados continuaram em programas de pós-graduação ao iniciar o doutorado e que $67,5 \%$ atuam na carreira docente. Em relação à estrutura do programa, $62,8 \%$ dos egressos afirmam que as metodologias de ensino utilizadas são adequadas e $67,4 \%$ afirmam ter uma boa relação com seu orientador.

Palavras-chave: Pós-graduação em contabilidade; Egressos; Ensino contábil.

\section{ABSTRACT}

Brazilian postgraduate degree in accounting began in 1970 and following worldwide trends, to ensure and increase the quality of programs, began in the 1990s the process of external evaluation. The model applied by the Coordination of Improvement of Higher Level Personnel (CAPES) is the result of a process of improvement of the quality of the programs. In addition to the external CAPES' evaluation, a program can be evaluated internally by monitoring the trajectory of its graduates and by their perception about their formation. This study aims to analyze the perception of the Graduate Program in Controllership and Accounting (PPGCC) of the Faculty of Economics, Administration and Accounting of Ribeirão Preto (FEARP-USP) regarding the course and its experience as a graduate. A websurvey was conducted with 43 graduates, representing $46.2 \%$ of the total until 2016 . The results indicated that $58.1 \%$ of the graduates continued in postgraduate programs when they started their doctorate and that $67.5 \%$ work in the teaching career. Regarding the structure of the program $62.8 \%$ of graduates say that the teaching methodologies used are adequate and $67.4 \%$ say they have a good relationship with their supervisor.

Keywords: Accounting Gradute School; Graduates; Accounting Education.

Recebido em: 04-07-2019 Aceito em: 22-10-2019

\section{INTRODUÇÃO}

A discussão institucional a respeito dos cursos de pós-graduação e sua formalização em cenário nacional foi iniciada com a Lei 4.024/61 - Lei de Diretrizes e Bases da Educação Nacional (LDB) - e aprovada em 1965 pelo Conselho Federal de Educação, por meio do Parecer no 977 (PELEIAS et al., 2007; ERDMANN; FERNANDES; TEIXEIRA, 2011).

A partir da década de 1990, houve expansão dos cursos de pós-graduação stricto sensu, alterando não só o número, mas também o perfil de mestres e doutores (VIOTTI et al, 2016) e levantando preocupações acerca de aspectos relacionados à qualidade e à necessidade de avaliar os novos programas e os já existentes, dando início às discussões sobre avaliações institucionais. As experiências de avaliação

\footnotetext{
* Doutor em Ciências Contábeis pela FEA/USP. Mestre em Engenharia (Engenharia de Produção) pela EESC-USP. Graduado em Ciências Contábeis pela Universidade de São Paulo. Professor do Departamento de Contabilidade da FEARP/USP.

"Doutorando em Controladoria e Contabilidade no PPGCC da FEA/USP. Mestre em Controladoria e Contabilidade no PPGCC da FEA-RP/USP. Bacharel em Ciências Contábeis pela FEA-RP/USP. E-mail: jp.resendelima@hotmail.com

" Pós-doutora em Educação pela UFSCar. Mestre e Doutora em Contabilidade e Controladoria pela Faculdade de Economia Administração e Contabilidade FEAUSP. Graduada em Administração de Empresas e em Ciências Contábeis. Professora Titular da Universidade de São Paulo.
} 
dos programas de pós-graduação tiveram início em 1976, com o objetivo de alavancar os programas e as pesquisas científicas e tecnológicas desenvolvidas no Brasil, sendo alterado e aprimorado ao decorrer dos anos (MOREIRA; HORTALE; HARTZ, 2004).

Desde 1998, a avaliação institucional dos programas de pós-graduação stricto sensu tem sido realizada de maneira externa aos programas pela Coordenação de Aperfeiçoamento de Pessoal de Nível Superior (CAPES) (SOARES; CASA NOVA, 2015). Além da avaliação externa realizada pela CAPES, os programas podem também realizar suas próprias avaliações, sendo uma possibilidade o acompanhamento de seus ex-alunos, os egressos (PAIXÃO; HASTENREITER FILHO, 2014).

A avaliação dos egressos e de suas percepções é uma maneira importante de avaliação, pois a avaliação destes egressos significa, na realidade, a avaliação do programa e suas práticas (GUIMARÃES; SLOMSKI; GOMES, 2010). Pode-se ainda avaliar um programa ou curso a partir da percepção dos egressos a respeito dos seus programas de origem (PAIXÃO; HASTERNREITER FILHO, 2014). Tais levantamentos realizados para acompanhar os egressos permitem ainda obter informações que subsidiam a manutenção de pontos positivos e potenciais melhorias para a proposta do programa, além de abranger fatores como objetivo, infraestrutura, integração com a sociedade e o mercado, entre outros, justificando os trabalhos realizados (CAMPOS; BORGES; ARAUJO 2014).

Especificamente na área de Contabilidade, o primeiro curso de pós-graduação, na modalidade stricto sensu em território brasileiro, foi o instituído pela Universidade de São Paulo (USP) na Faculdade de Economia, Administração e Contabilidade (FEA) em 1970 e, até o ano de 2007, foi o único curso de doutorado na área (PELEIAS et al., 2007). Acerca da expansão e consolidação da área, os dados da CAPES (CAPES, 2016) apontam a existência de 27 programas de pós-graduação em contabilidade no Brasil.

Diante do cenário de expansão, faz-se necessário avaliar se esse aumento quantitativo e expressivo de cursos está sendo acompanhado de um aumento qualitativo, mantendo, e, sempre que possível, aumentando a qualidade dos cursos oferecidos. Assim, o presente estudo tem o objetivo de propor um instrumento que visa analisar a percepção de estudantes egressos de programas de pós-graduação. Adicionalmente, o presente artigo aplica e discute o instrumento proposto a partir da aplicação do mesmo no Programa de Pós-Graduação em Controladoria e Contabilidade (PPGCC) da Faculdade de Economia, Administração e Contabilidade de Ribeirão Preto (FEARP-USP), a respeito do programa e sua experiência como pós-graduado.

O presente trabalho contribui de maneira prática, propondo um instrumento que leva em consideração fatores levantados na literatura para avaliação de programas de pós-graduação em contabilidade. Além do instrumento, o trabalho apresenta insights de mestres já titulados sobre os diversos fatores da experiência acadêmica na pós-graduação em contabilidade, contribuindo para a literatura acerca desse ambiente acadêmico e para os programas e órgãos reguladores que podem tomar essas respostas como base para revisão das normas da área e dos seus respectivos programas.

O trabalho estrutura-se em cinco seções, tendo início nessa introdução. $\mathrm{Na}$ segunda seção, apresenta-se a base teórica do trabalho com aspectos históricos sobre a pós-graduação em Contabilidade no Brasil, o processo de avaliação de PPGs e estudos correlatos. Na terceira seção, são apresentados os procedimentos metodológicos adotados. Por fim, na quarta e quinta seção, apresentam-se, respectivamente, os resultados e as considerações finais do trabalho.

\section{REFERENCIAL TEÓRICO}

A pós-graduação stricto sensu, na área de contabilidade, foi criada na Universidade de São Paulo (USP) em 1970, sediado na FEA/USP, que, em 1978, iniciou o primeiro curso de doutorado em contabilidade (PELEIAS et. al., 2007). O desenvolvimento, consolidação e expansão da área é recente, visto que, até o final da década de 1990, existiam apenas seis programas de mestrado e, até o ano de 2007, um programa de doutorado (MARTINS, 2012).

O segundo programa de doutorado na área foi implantando no ano de 2008, por meio de uma ação Multiinstitucional e Inter-regional entre a Universidade de Brasília (UnB), Universidade Federal da Paraíba (UFPB) e Universidade Federal do Rio Grande do Norte (UFRN), (VENDRAMIN; ARAUJO, 2014). Assim, os programas se constituíram atendendo às demandas regionais e partindo da formação destes programas que foram os pioneiros na formação dos primeiros titulados e que seriam os multiplicadores dos programas pelo país. Hoje, existem vinte e oito programas de pós-graduação em contabilidade (CAPES, 2016).

Até o ano de 2017, foram encontrados 27 programas de pós-graduação em Ciências Contábeis, que contam com cerca de 370 professores credenciados como orientadores (LIMA, VENDRAMIN; CASA NOVA, 2017). 


\subsection{Avaliação Institucional no contexto da pós-graduação}

O processo de avaliação institucional no âmbito da pós-graduação brasileira foi iniciado em 1976, quando foi implantando o Sistema de Avaliação da Pós-Graduação, com o intuito de desenvolver não só a pós-graduação em si, mas também a pesquisa científica e tecnológica no Brasil (MOREIRA, 2009). O modelo implantado em 1976 sofreu diversas alterações com o passar do tempo, até resultar no adotado pela CAPES a partir de 1998.

O modelo adotado pela CAPES para avaliações externas classifica os programas com notas que vão de um a sete, observando cinco critérios: (i) proposta do programa, (ii) corpo docente, (iii) corpo discente, teses e dissertações, (iv) produção intelectual e, (v) inserção social. Cada um desses cinco tem peso diferente, sendo $0 \%, 20 \%, 35 \%, 35 \%$ e $10 \%$, respectivamente (SOARES; NOVA, 2015). O peso atribuído aos critérios da avaliação CAPES é alvo de diversas críticas, uma vez que a produção científica - seja por meio da produção de teses e dissertações, seja por meio da produção intelectual - soma $70 \%$ da avaliação total, levando os programas à mentalidade do "publish or perish", aumentando a pressão para os docentes e para os alunos publicarem, mas sem se preocupar com a qualidade dessas publicações.

Outra crítica que pode ser feita ao modelo é o fato de a inserção social do programa ter peso de apenas $10 \%$, assim, o impacto que o programa tem na região em que se encontra é considerado de maneira muito tímida se comparado com o peso atribuído às produções científicas. No que diz respeito à periodicidade dessas avaliações, a CAPES revisou o intervalo de tempo devido à expansão dos cursos, passando, assim, de avaliações trienais para quadrienais.

Além deste sistema de avaliação, os programas podem buscar outras formas de se autoavaliarem. $\mathrm{Na}$ literatura nacional, é possível encontrar a adoção da Análise Envoltória de Dados para realizar tal avaliação (LINS; ALMEIDA; BARTHOLO JUNIOR, 2004) e de decisão multicritério (MIRANDA; ALMEIDA, 2004). Há, ainda, nas avaliações, o acompanhamento da trajetória dos seus egressos que possibilita que 0 programa avalie suas práticas e identifique os casos de (in)sucesso. A avaliação dos egressos tem se tornado uma demanda da CAPES e deve ser incluída nas avaliações externas do programa (PAIXÃO; HASTENREITER FILHO, 2014; CAMPOS; BORGES; ARAUJO, 2014).

\subsection{Avaliação dos programas de pós-graduação: o egresso em foco}

De acordo com o levantamento teórico realizado, foram dois principais procedimentos para a avaliação das atividades dos egressos dos programas de pós-graduação na área de negócios: (i) o desenvolvimento de levantamentos (survey) com os egressos, avaliando diversos fatores, principalmente sua situação social/econômica e a evolução que o programa proporcionou ao egresso; e (ii) levantamento documental dos currículos Lattes para avaliar, principalmente, sua atividade profissional e seu estágio de publicações, visto que a plataforma Lattes representa um padrão nacional no registro da vida acadêmica de docentes e estudantes brasileiros do ensino superior.

Especificamente sobre estudos de levantamentos com egressos de programas de pós-graduação na área contábil, foram observados os estudos de Cunha, Cornachione Júnior, Martins (2010) com doutores da FEA/USP, Martins e Monte (2011) com Mestres do programa Multi-institucional da UNB/UFPB/UFRN e Quintal et al. (2012) com Mestres da UERJ. Os principais resultados encontrados por tais trabalhos são apresentados no quadro 1.

Quadro 1 - Trabalhos com levantamento

\begin{tabular}{|c|c|l|}
\hline Autores & Foco do estudo & \multicolumn{1}{c|}{ Principais resultados } \\
\hline \multirow{2}{*}{$\begin{array}{l}\text { A maioria dos egressos pesquisados pelos autores era do sexo masculino; estavam } \\
\text { concentrados, principalmente, no estado de São Paulo, e o restante distribuía-se em }\end{array}$} \\
$\begin{array}{c}\text { outros 12 estados; no que tange à atividade profissional, 68,9\% dos egressos } \\
\text { atuavam na área acadêmica, sendo que 51,1\% do total eram de Instituições de } \\
\text { Ensino Superior (IES) públicas. }\end{array}$
\end{tabular}

Fonte: elaboração própria 
As pesquisas de acompanhamento de egressos dos programas de pós-graduação são também desenvolvidas a partir do acompanhamento de seus currículos Lattes, principalmente para avaliar sua produção científica após o término de seu programa, sendo uma síntese dessas pesquisas apresentadas no Quadro 2.

Quadro 2 - Trabalhos com análise de currículo

\begin{tabular}{|c|c|c|}
\hline Autores & Foco do estudo & Principais resultados \\
\hline 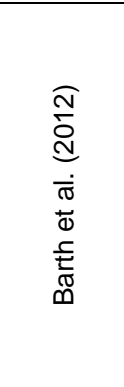 & $\begin{array}{c}\text { Atividade de docência e a } \\
\text { evolução da produção } \\
\text { científica de } 319 \text { mestres } \\
\text { formados em quatro } \\
\text { programas de mestrado em } \\
\text { contabilidade da região sul do } \\
\text { Brasil. }\end{array}$ & $\begin{array}{l}\text { O levantamento efetuado por Barth et al. (2012) demonstrou que (i) a maioria dos } \\
\text { egressos já possuía o vínculo com a docência, evidenciando a busca do curso de } \\
\text { mestrado como instrumento de atualização do conhecimento e desenvolvimento do } \\
\text { pensamento crítico, possibilitando o avanço na carreira; (ii) os mestres iniciaram o } \\
\text { programa de mestrado sem um número expressivo de publicações ( } 94 \text { ao todo), mas, } \\
\text { hoje, somam juntos } 3.510 \text { artigos publicados em periódicos ou eventos, } \\
\text { representando uma média de } 11,25 \text { artigos por egresso. Entretanto, } 226 \text { mestres } \\
\text { (72,44\% do total) estão abaixo desta média e } 83 \text { egressos não possuem pelo menos } \\
\text { duas publicações. Os autores indicam preocupação em relação à qualidade das } \\
\text { publicações, muitas vezes ocorridas em eventos e periódicos não pontuados pela } \\
\text { coordenadoria ou com pontuação aquém do esperado pelo critério CAPES no quesito } \\
\text { de 'muito bom'. }\end{array}$ \\
\hline 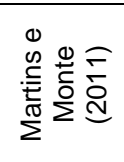 & $\begin{array}{l}\text { Desenvolver um modelo para } \\
\text { avaliar quais variáveis } \\
\text { influenciariam a produção } \\
\text { científica dos egressos. }\end{array}$ & $\begin{array}{l}\text { Os resultados, obtidos por meio da análise de regressão efetuada, indicou que as } \\
\text { principais variáveis que influenciam esta publicação foram: possuir doutorado; } \\
\text { possuir doutorado em contabilidade; e residir no estado integrante do programa. Já } \\
\text { na análise de publicações em periódico, somente a variável 'ter doutorado' mostrou- } \\
\text { se significativa para expor o aumento de publicações em periódicos. }\end{array}$ \\
\hline
\end{tabular}

Fonte: elaboração própria

Estas pesquisas demonstram que, de certa forma, os programas estão buscando formas de acompanhamento de egresso, podendo resultar em medidas de correções internas no programa. Quando o nível de satisfação é alto, sinalizam, também, que o programa está atingindo de forma positiva ao seu objetivo.

\section{PROCEDIMENTOS METODOLÓGICOS}

O delineamento desta pesquisa foi baseado na tipologia proposta por Beuren (2006). Dessa forma, no tocante aos objetivos, a pesquisa caracteriza-se como descritiva, pois descreve o comportamento da população pesquisada. Quanto aos procedimentos, a pesquisa foi um levantamento e, em relação à abordagem do problema, é uma pesquisa quantitativa, já que faz uso de instrumentos estatísticos para análise dos dados.

No que diz respeito ao procedimento de pesquisa, foi realizado um levantamento realizado de maneira online, assim, caracterizado como websurvey. Um dos principais pontos negativos da websurvey, de acordo com Dillmann (2000), é o risco de não se conseguir os endereços eletrônicos da população almejada. Para mitigar este problema, no caso desta pesquisa, os endereços de e-mails foram inicialmente levantados a partir da base de dados existente no programa de pós-graduação. Observou-se que cerca de $25 \%$ dos e-mails já eram inválidos, assim, buscaram-se outras formas de contato, e a principal delas se deu por meio de redes sociais, principalmente Facebook e Linkedln. Após este processo, os contatos finalizaram em $97,8 \%$ dos egressos, sendo que dois egressos não foram localizados. Assim, da população de 93 egressos, obteve-se algum tipo de contato de 91 deles para envio do questionário.

A primeira onda de envio de e-mails foi realizada em julho de 2015, e outras duas no mês de agosto do mesmo ano. A população da pesquisa foi tomada com base nos alunos que concluíram o programa até maio de 2015, porém a última defesa do período em questão foi realizada em novembro de 2014. O último ano de entrada no programa para composição da população foi 2013.

O questionário de pesquisa aplicado aos egressos foi construído partindo-se do objetivo da pesquisa e da revisão de literatura, principalmente a partir dos trabalhos de Cunha, Cornachione Júnior, Martins (2010), Martins e Monte (2011), Barth et al. (2012) e Quintal et al. (2012). Dessa forma, o questionário foi estruturado de forma a avaliar aspectos referentes ao ambiente acadêmico e de ensino durante seu programa de pós, aspectos gerais de sua formação, bem com suas atividades de pesquisa durante e após o programa.

O instrumento de pesquisa foi elaborado a partir de dois grupos de questionamentos de avaliação do programa e da experiência do egresso. O primeiro com questões de avaliação de concordância, em uma escala de Likert de cinco pontos de concordância plena a discordância plena; e o segundo, com avaliação por notas de um a dez. Foram avaliados três construtos: "Ambiente Acadêmico e Ensino" com sete questões, "Atividades de Pesquisa", com seis questões e "Formação geral", com duas questões baseadas na escala Likert e nove, com notas de um a dez. 
A pesquisa teve enfoque central na análise quantitativa dos dados, fazendo, além das estatísticas descritivas, também análises de diferenças de grupos, usando testes não paramétricos de Qui-quadrado para questões com respostas não numéricas, e o teste de Mann-Whitney para respostas numéricas.

Caber ressaltar que, apesar do trabalho ter uma abordagem quantitativa, o questionário apresentou um campo aberto para colocações que os entrevistados desejassem informar de forma voluntária. Algumas dessas declarações foram utilizadas na descrição dos resultados, apenas como forma de representar alguns achados. O trabalho não teve o objetivo de análise destes conteúdos de forma qualitativa.

Para realizar o estudo, o instrumento foi aplicado aos egressos do programa de pós-graduação em controladoria e contabilidade da FEARP-USP. O programa em questão foi criado em 2006, como parte de atendimento a uma demanda existente e com o propósito de formar mestres na área de controladoria e contabilidade; e a partir de 2013, o programa iniciou o oferecimento do curso de doutorado. As linhas de pesquisas iniciais perduram até nos dias atuais, sendo elas: contabilidade financeira e finanças e controladoria. Até o ano de 2017, foram titulados 131 mestres e quatro doutores.

\section{ANÁLISE E DISCUSSÃO DOS RESULTADOS}

Visando dar o devido aprofundamento às análises dos dados, a presente seção é dividida em quatro partes. Inicialmente, são apresentados os participantes da pesquisa, assim como informações acerca do financiamento de seus projetos de pesquisas, da formação inicial, da cidade de origem etc. Em seguida, são apresentadas as discussões que permeiam o ambiente acadêmico e as atividades relacionadas ao ensino. Por fim, analisam-se as atividades de pesquisa e a percepção dos egressos acerca de sua formação de maneira geral.

\subsection{Caracterização da amostra}

A população deste estudo totaliza 93 egressos do curso de mestrado, cujas defesas ocorreram entre 2005 e 2014. Foram obtidas 43 respostas ao total, assim, a amostra do estudo representa $46,2 \%$ da população estudada. Para análises posteriores desta pesquisa, os egressos foram separados por ano de defesa, em dois grupos. O primeiro dos concluintes entre 2006 e 2010, período inicial do programa, e um segundo com concluintes entre 2011 e 2014, visto que não ocorreram defesas no período pesquisado em 2015.

Em termos de localização, $72,1 \%$ dos egressos residiam no estado de São Paulo, e 16,3\% estão no estado de Minas Gerais no período da pesquisa. O restante está distribuído entre o Distrito Federal, Paraíba e Paraná. Há, ainda, um egresso residindo no exterior, Portugal. As principais cidades são Ribeirão Preto $(53,5 \%)$ e São Paulo (7\%), enquanto os demais estão distribuídos em outras 14 cidades, principalmente de São Paulo e Minas Gerais. Percebe-se, assim, que o maior impacto do programa ocorre na própria cidade, mas que, também, ocorre em regiões próximas e até internacionalmente, em alguns casos.

No tocante à formação inicial dos egressos, $51,2 \%$ são graduados na FEARP-USP, principalmente no curso de Ciências Contábeis (95,5\%). Dos 48,8\% que tem origem externa à FEARP-USP, 71,4\% também têm formação em Ciências Contábeis e os demais nas áreas de Administração, Economia e Matemática. Desta forma, $83,7 \%$ dos egressos pesquisados têm formação de graduação em Ciências Contábeis. Esta alta taxa de alunos ingressantes no programa, oriundos de uma graduação em Ciências Contábeis, é também observada nos trabalhos de Cunha, Cornacchione Jr. e Martins (2010), Martins e Monte (2011) e Quintal et al. (2012), o que pode indicar o alto interesse de continuar os estudos na área, mas a baixa atratividade de alunos de áreas afins.

No que tange ao apoio financeiro de órgãos de fomento durante a permanência no programa, $62,8 \%$ solicitaram bolsa, contudo 9,3\% não conseguiram. Assim, 53,5\% dos egressos obtiveram apoio financeiro na forma de bolsa durante o período em que cursaram a pós-graduação, e $37,2 \%$ não solicitaram. Dos $53,5 \%$ que obtiveram apoio financeiro, $87 \%$ foram bolsas CAPES/Conselho Nacional de Desenvolvimento Científico e Tecnológico (CNPq), 4,3\% Fundação de Amparo à Pesquisa do Estado de São Paulo (FAPESP) e $8,7 \%$ de outras fontes.

O percentual de alunos que não tiveram bolsas é maior no primeiro período do curso (2006 a 2010), sendo $70,6 \%$ contra $30,8 \%$ dos egressos do período de 2011 a 2014. Acredita-se que os egressos tenham desenvolvidos algum tipo de atividade remuneratória durante seu período de mestrado. Dessa forma, avalia-se que as condições de apoio aos alunos melhoraram durante o período analisado, o que pode ser considerado um reflexo da consolidação do programa, visto que, com base na avaliação do programa, é alocado determinado número de bolsas (CAPES, 2017).

Cabe ressaltar que, na região de Ribeirão Preto, há mais de 10 Instituições de Ensino Superior (IES) que oferecem o curso de graduação em ciências contábeis, e que estas sempre solicitam indicação de alunos e egressos para preenchimento de vagas de docentes, reforçando o impacto que o programa tem causado na região em que se localiza e tornado referência na mesma. 
Em relação à continuidade na pós-graduação, $58,1 \%$ dos egressos indicaram ter prosseguido os estudos em programas de doutorado, sendo que $37,2 \%$ iniciaram o doutorado na área de Contabilidade e Controladoria e 20,9\% em Administração. Esta taxa de egressos iniciando o curso de Doutorado é maior do que as taxas observadas no estudo de Martins e Monte (2011), e pode ser explicada pela maior oferta de cursos de doutorado na área, a partir de 2007. Esta categorização de continuidade em programas de doutorado foi utilizada para análises nesta pesquisa.

No quesito empregabilidade, $86 \%$ dos respondentes indicaram estar empregados e dos $14 \%$ que não estão empregados, 7\% estavam procurando emprego a menos de 6 meses, e outros 7\% não estavam procurando emprego. Entre os que indicaram estar empregados na época da pesquisa, $18,9 \%$ atuavam como empresários ou autônomos: $67,5 \%$ na atividade docente - sendo $24,3 \%$ em instituições públicas e $43,2 \%$ em instituições privadas -, $18,9 \%$ na iniciativa pública, $21,6 \%$ na iniciativa privada e apenas $2,7 \%$ em instituições do terceiro setor.

As taxas encontradas de atividade profissional ligadas à docência são superiores às encontradas nos egressos dos estudos de Martins e Monte (2011) e Quintal et al. (2012), que eram de $32 \%$, e 44,8\%, respectivamente. Conforme já exposto, a região tem alta demanda por docentes da área, o que resulta em $67 \%$ dos egressos que moram em Ribeirão Preto atuarem na educação superior.

Observa-se que $24,3 \%$ dos egressos têm mais de uma forma de atuação. Isso pode ser explicado pelo fato de que $56,3 \%$ dos que atuam na docência em instituições privadas também atuarem como autônomos em entidades do setor público e privado. Destaca-se, ainda, que, em relação aos docentes que atuam em instituições privadas, 37,5\% deles atuam em mais de uma instituição.

Questionados se atuavam na sua área de formação do mestrado, 91,9\% indicaram que sim, e os $8,1 \%$ que indicaram não atuar na área apontaram estar atuando, principalmente, em áreas mais ligadas à administração.

Em termos de renda, observa-se, pela tabela 1, que $62,2 \%$ dos egressos indicaram renda entre $R \$ 2.000,00$ e $R \$ 7.500,00$. Com base nos percentuais indicados de renda, estimou-se uma renda média de $\mathrm{R} \$ 9.300,00$.

Tabela 1 - Renda dos respondentes

\begin{tabular}{lc}
\hline \multicolumn{1}{c}{ Faixa Salarial } & $\%$ \\
\hline De $R \$ 2.000,01$ a $R \$ 4.000,00$ & $13,5 \%$ \\
De $R \$ 4.000,01$ a $R \$ 6.000,00$ & $27,0 \%$ \\
De $R \$ 6.000,01$ a $R \$ 7.500,00$ & $21,6 \%$ \\
De $R \$ 7.500,01$ a $R \$ 10.000,00$ & $13,5 \%$ \\
De $R \$ 10.000,01$ a $R \$ 15.000,00$ & $5,4 \%$ \\
De $R \$ 15.000,01$ a $R \$ 25.000,00$ & $16,2 \%$ \\
De $R \$ 25.000,01$ a $R \$ 50.000,00$ & $2,7 \%$ \\
\hline \multicolumn{2}{c}{ Fonte: Elaboração própria com dados da pesquisa }
\end{tabular}

A título de comparação, para demonstrar a evolução que a formação no mestrado oferece, esta renda média é $20 \%$ superior aos egressos do curso de graduação em ciências contábeis desta mesma instituição, conforme demonstram Miranda, Pazello e Lima (2015).

\subsection{Ambiente acadêmico \& ensino}

A primeira parte das análises refere-se a dois elementos importantes da pós-graduação: o ambiente acadêmico e o ensino. Lima, Vendramin e Casa Nova (2017) mostram que o ambiente acadêmico pode levar ao desenvolvimento do sentimento de insegurança e desalojamento, se colocando como mais uma barreira no processo de titulação.

A primeira questão deste bloco, conforme a tabela 2, procurava detectar se havia integração entre os alunos e docentes do programa. Observou-se uma concordância plena e parcial de 55,8\%, mas também uma discordância plena e parcial de 30,2\%, indicando dois possíveis grupos de alunos: os que tinham forte integração com os docentes e os que tinham uma relação mais distante. A integração entre docentes e discentes é um ponto pertinente para qualquer instituição de ensino, uma vez que, de acordo com Ribeiro (2010), a construção de conhecimentos resulta das interações entre docentes e discentes - tanto dentro da sala de aula quanto fora dela. 
Tabela 2 - Análise do ambiente acadêmico

\begin{tabular}{ccccccc}
\hline Afirmativa & $\mathbf{1}$ & $\mathbf{2}$ & $\mathbf{3}$ & $\mathbf{4}$ & $\mathbf{5}$ & TOTAL \\
\hline $\begin{array}{c}\text { Há forte integração entre os alunos do } \\
\text { programa e os docentes. }\end{array}$ & $11,63 \%$ & $18,60 \%$ & $13,95 \%$ & $37,21 \%$ & $18,60 \%$ & $100,00 \%$ \\
$\begin{array}{c}\text { Os orientadores do programa não estão } \\
\text { próximos de seus orientados. }\end{array}$ & $27,91 \%$ & $39,53 \%$ & $13,95 \%$ & $13,95 \%$ & $4,65 \%$ & $100,00 \%$ \\
\hline
\end{tabular}

Fonte: dados da pesquisa

A segunda questão analisava a proximidade entre orientadores e orientados e observou-se uma discordância plena e parcial de $67,4 \%$ e uma concordância plena e parcial de $18,6 \% \%$. Segundo Santos Filho e Carvalho (1991), Berndt (2003) e Lima et al. (2017), o orientador pode ser visto como um dos principais fatores de (in)sucesso durante a pós-graduação. Tal proximidade com os orientadores pode ser um dos componentes que explica a baixa taxa de evasão do programa do período $(18,89 \%$,$) . Nas duas$ questões desta categoria, não foram encontradas diferenças significativas de avaliação.

No segundo grupo de questões, expostos na tabela 3, foram analisados aspectos referentes ao ensino ofertado pelo programa. Tais questionamentos abrangem aspectos da grade do programa e das atividades em sala de aula, tidos como fatores importantes para a experiência num programa de pósgraduação (LIMA; VENDRAMIN; CASA NOVA, 2017).

Tabela 3 - Análise da percepção sobre elementos do ensino

\begin{tabular}{ccccccc}
\hline Afirmativa & $\mathbf{1}$ & $\mathbf{2}$ & $\mathbf{3}$ & $\mathbf{4}$ & $\mathbf{5}$ & TOTAL \\
\hline $\begin{array}{c}\text { A carga de disciplinas do programa é } \\
\text { elevada. }\end{array}$ & $2,33 \%$ & $9,30 \%$ & $11,63 \%$ & $39,53 \%$ & $37,21 \%$ & $100,00 \%$ \\
$\begin{array}{c}\text { Existem sobreposições de conteúdos nas } \\
\text { disciplinas. }\end{array}$ & $11,63 \%$ & $37,21 \%$ & $23,26 \%$ & $27,91 \%$ & $0,00 \%$ & $100,00 \%$ \\
\hline $\begin{array}{c}\text { O nível de aulas expositivas pelos docentes é } \\
\text { adequado. }\end{array}$ & $6,98 \%$ & $25,58 \%$ & $4,65 \%$ & $39,53 \%$ & $23,26 \%$ & $100,00 \%$ \\
$\begin{array}{c}\text { As avaliações da aprendizagem realizadas } \\
\text { durante o curso são compatíveis com os } \\
\text { conteúdos ou temas trabalhados pelos } \\
\text { professores. }\end{array}$ & $0,00 \%$ & $25,58 \%$ & $11,63 \%$ & $51,16 \%$ & $11,63 \%$ & $100,00 \%$ \\
\hline $\begin{array}{c}\text { O nível de internacionalização do programa é } \\
\text { alto. }\end{array}$ & $18,60 \%$ & $34,88 \%$ & $25,58 \%$ & $11,63 \%$ & $9,30 \%$ & $100,00 \%$ \\
\hline
\end{tabular}

Fonte: dados da pesquisa

O questionamento com maior grau de concordância foi a questão a respeito da carga horária das disciplinas do programa, em que a concordância plena e parcial totalizou $76,7 \%$ dos egressos. Apesar das alterações que o programa sofreu nos últimos anos, não se observa diferença de avaliação entre os egressos de diferentes anos.

Nos programas de pós-graduação, as metodologias de ensino utilizadas nem sempre são as mesmas das utilizadas na graduação; muitas vezes, a participação do docente é reduzida nas aulas expositivas, pela utilização de seminários ou discussões dirigidas. Questionados se o nível de aulas expositivas pelos docentes seria adequado, houve uma concordância plena e parcial de 62,8\%.

Como forma de avaliar o currículo do curso, questionou-se se haveria sobreposição de conteúdos nas disciplinas e houve discordância plena e parcial de $48,8 \%$, e a concordância parcial foi de $27,9 \%$. $O$ processo avaliativo foi também questionado, e observa-se que $25,6 \%$ dos respondentes discordaram parcialmente; enquanto $62,8 \%$ concordaram parcial e plenamente.

Por fim, o nível de internacionalização do programa apresentou concordância parcial e plena de $20,9 \%$ e a discordância parcial e plena foi de 53,5\%. Em termos de atividades internacionais, $11,6 \%$ dos egressos indicaram terem desenvolvido alguma atividade internacional durante ou decorrente das atividades que desenvolveu durante seu programa de mestrado.

Não foram encontradas diferenças significativas de avaliação nesta primeira categoria, nem entre os que iniciaram doutorado após o mestrado da FEARP, nem entre os alunos agrupados por período de término do programa. Observa-se que há uma manutenção do nível de satisfação em relação aos aspectos dos conteúdos e de que como foram repassados aos alunos, ao mesmo passo que se observam pontos a serem trabalhados pelo programa (a sobreposição das disciplinas e o nível de internacionalização). 


\subsection{Atividades de pesquisa}

Inicialmente, foi questionado se na percepção do respondente o programa contava com grupos de pesquisa forte, com $41,86 \%$ de discordância e $27,91 \%$ de indiferença, conforme demonstra a Tabela 4 . Destaca-se que, na FEARP-USP, existem alguns grupos de pesquisa: alguns específicos da área contábil; outros têm caráter interdisciplinar em que docentes e alunos de todos os cursos participam. Dado caráter específico de alguns grupos - como cooperativismo, ensino contábil de gestão pública -, muitas vezes alunos de mestrado podem não conhecer ou não se interessar em participar em tais grupos, o que ajuda a explicar o alto nível de discordância da questão.

Tabela 4 - Análise das atividades de pesquisa

\begin{tabular}{|c|c|c|c|c|c|c|}
\hline Afirmativa & 1 & 2 & 3 & 4 & 5 & TOTAL \\
\hline $\begin{array}{c}\text { Grupos de estudos e pesquisas são fortes no } \\
\text { meu programa. }\end{array}$ & $16,28 \%$ & $25,58 \%$ & $27,91 \%$ & $11,63 \%$ & $18,60 \%$ & $100,00 \%$ \\
\hline $\begin{array}{l}\text { São oferecidas oportunidades para os pós- } \\
\text { graduandos participarem de congressos e } \\
\text { eventos da sua área de formação. }\end{array}$ & $6,98 \%$ & $16,28 \%$ & $18,60 \%$ & $25,58 \%$ & $32,56 \%$ & $100,00 \%$ \\
\hline $\begin{array}{l}\text { Publiquei trabalhos frutos de minha } \\
\text { dissertação/tese em CONGRESSOS }\end{array}$ & $32,56 \%$ & $16,28 \%$ & $51,16 \%$ & $0,00 \%$ & $0,00 \%$ & $100,00 \%$ \\
\hline $\begin{array}{l}\text { Publiquei trabalhos frutos de minha } \\
\text { dissertação/tese em } \\
\text { REVISTAS/PERIÓDICOS }\end{array}$ & $32,56 \%$ & $32,56 \%$ & $34,88 \%$ & $0,00 \%$ & $0,00 \%$ & $100,00 \%$ \\
\hline $\begin{array}{l}\text { Considerando os últimos } 12 \text { meses em } \\
\text { relação às suas publicações em } \\
\text { CONGRESSOS }\end{array}$ & $58,14 \%$ & $32,56 \%$ & $6,98 \%$ & $2,33 \%$ & $0,00 \%$ & $100,00 \%$ \\
\hline $\begin{array}{l}\text { Considerando os últimos } 12 \text { meses, em } \\
\text { relação às suas publicações em } \\
\text { REVISTAS/PERIÓDICOS }\end{array}$ & $25,58 \%$ & $13,95 \%$ & $60,47 \%$ & $0,00 \%$ & $0,00 \%$ & $100,00 \%$ \\
\hline
\end{tabular}

Fonte: dados da pesquisa

Para avaliar a atividade de pesquisa dos egressos, foram feitos questionamentos sobre suas publicações, tanto as que foram frutos de sua dissertação quanto de atividades recentes de pesquisa, também expostas na tabela 4.

No que tange à publicação da dissertação em congressos, $58,1 \%$ dos egressos indicaram terem publicado trabalhos de sua dissertação. Em termos de publicações em periódicos, $39,5 \%$ indicaram ter feito publicações, 30,2\% indicaram que seus trabalhos estão em fase de avaliação de um periódico, e 30,2\% indicaram não ter publicado trabalho fruto de suas dissertações em um periódico. Considerando a não publicação da dissertação em congressos ou periódicos, observa-se que isso ocorreu com $16,3 \%$ dos egressos.

Pelo teste de Qui-quadrado, observa-se a diferença significativa de publicações da dissertação entre os egressos formados entre 2006 a 2010 e os formados entre 2011 e 2014. Enquanto 47,1\% do primeiro grupo indicaram não ter publicado suas dissertações em periódicos, esta taxa cai para 19,2\% no segundo grupo. Isso pode ser avaliado como um processo de maior compreensão dos docentes e orientados acerca da importância da produção científica das dissertações do programa que certamente contribuiu para a sua consolidação e aumento de nota em avaliações seguintes.

Quanto a publicações de forma geral, nos últimos 12 meses anteriores à pesquisa, independentemente da dissertação, observa-se que $32,6 \%$ indicaram ter feito mais de uma publicação em congressos, $16,3 \%$ em apenas um congresso e 51,2\% não tiveram nenhuma publicação em congressos.

Ao se comparar os egressos que indicaram ter ou estar fazendo um doutorado com os que não indicaram, observa-se diferença significativa pelo teste de Qui-quadrado. A taxa de não publicação dos que não continuaram um programa foi de $77,3 \%$, enquanto os que continuaram esta taxa foi de apenas $23,8 \%$, retomando a ideia de publicações ligadas à academia, por exigência do programa de doutorado ou não.

Em termos de publicações em periódicos nos últimos 12 meses anteriores à pesquisa, observa-se que $32,6 \%$ tiveram algum artigo, outros $32,6 \%$ indicaram ter feito submissões, mas que aguardavam parecer de avaliação, e outros 34,9\% não fizeram qualquer submissão. Observam-se diferenças significativas, pelo teste de Qui-quadrado, ao se avaliar egressos com e sem continuidade no doutorado. 
Apenas $9,5 \%$ dos que continuaram a pós-graduação iniciando o doutorado não tiveram qualquer publicação ou submissão, já entre os que não continuaram, esta taxa foi de $59,1 \%$.

Considerando as submissões em congressos e periódicos, observa-se que $32,6 \%$ dos egressos não tiveram esforços de publicações observados. O que se observa é que o esforço de publicação é contínuo entre os que indicaram ser docentes, principalmente os de IES pública. Em relação aos que estão ligados a atividades fora da área de ensino e pesquisa pouco ou nada é observado, ou seja, o interesse pela atividade de pesquisa não foi continuado após o fim do programa de mestrado.

Foi avaliado se os egressos tiveram premiações acadêmicas. E 25,6\% indicaram que tiveram premiações, fruto do trabalho desenvolvido no programa. Outros $14,0 \%$ indicaram premiações, mas que não foram fruto de seus projetos de mestrado. Já $60,5 \%$ indicaram não ter recebido qualquer premiação acadêmica.

Ainda observando a atividade acadêmica dos egressos, questionaram-se os hábitos de atualização do currículo Lattes. Observa-se que 58,1\% indicam atualizar seus lattes de forma contínua, 32,6\% indicam que após o mestrado atualizaram poucas vezes, $7,0 \%$ indicaram nunca mais ter atualizado o lattes após a defesa, e um egresso indicou ter cancelado o lattes após o fim do programa.

Observa-se diferença significativa de atualização do lattes entre os que deram continuidade em programas de doutorado. Entre os que continuaram o doutorado, a taxa de atualização contínua foi de $85,7 \%$, enquanto que, entre os outros, esta taxa foi de $31,8 \%$. A maior utilização também é observada entre os que atuam na docência, e novamente entre os que estão no mercado de trabalho não acadêmico é observada pouca importância a sua atualização.

Dados como estes são importantes para ter conhecimento sobre o resultado de pesquisas e a veiculação destes resultados em congressos nacionais e internacionais e nos periódicos acadêmicos. Importante também para balizar a coordenação do curso no tocante ao cumprimento dos objetivos e propostas almejadas pelo egresso do programa.

\subsection{Formação geral}

A última parte do questionário visava analisar questões de formação para atuação profissional docência ou mercado profissional - e o nível de satisfação geral com o programa.

Tabela 5 - Análise de componentes de formação geral

\begin{tabular}{ccccccc}
\hline Afirmativa & $\mathbf{1}$ & $\mathbf{2}$ & $\mathbf{3}$ & $\mathbf{4}$ & $\mathbf{5}$ & TOTAL \\
\hline $\begin{array}{c}\text { O programa reflete as necessidades do } \\
\text { mercado. }\end{array}$ & $9,30 \%$ & $23,26 \%$ & $11,63 \%$ & $48,84 \%$ & $6,98 \%$ & $100,00 \%$ \\
$\begin{array}{c}\text { A participação em atividades relacionadas à } \\
\text { docência é importante para a formação do } \\
\text { pós-graduando, independente da área de } \\
\text { atuação. }\end{array}$ & $2,33 \%$ & $0,00 \%$ & $4,65 \%$ & $18,60 \%$ & $74,42 \%$ & $100,00 \%$ \\
\hline
\end{tabular}

Fonte: dados da pesquisa

Na primeira questão, exposta na tabela 5 , obteve-se $32,6 \%$ de discordância parcial plena. Em termos de concordância, ela foi de $48,8 \%$ de forma parcial e somente $7,0 \%$ de forma plena. Não foram observadas diferenças significativas de avaliação. Esse alto grau de discordância retrata o desalinhamento entre a academia e o mercado de trabalho, podendo reforçar a ideia de que o mestrado é especificamente para atuação na docência e na pesquisa. Esse é um dos pontos que os programas precisam rever, pois, cada vez mais, o mercado exige e absorve profissionais com titulações mais altas devido à complexidade e às rápidas mudanças da sociedade em que vivemos.

$\mathrm{Na}$ questão seguinte deste bloco, 93,3\% dos egressos concordaram parcial e plenamente com a questão, e somente 2,3\% discordaram. Cabe ressaltar que o programa da FEARP, a partir de 2015, passou a ofertar a disciplina "Didática do Ensino Contábil", além de contar com o Programa de Aperfeiçoamento de Ensino (PAE) no qual o aluno é exposto a uma Etapa de Preparação Pedagógica que visa prepará-lo para entrar em sala de aula como estagiário docente em semestres posteriores. Quintal et al. (2012) retratou a importância do estágio docente percebida pelos egressos do programa analisado.

Ainda dentro desta linha, foi deixado um campo aberto e optativo para que os alunos indicassem se, em relação ao programa de pós que cursaram, acreditavam que existiriam deficiências no programa em relação às demandas da sociedade. Obteve-se opinião de $37,2 \%$ dos respondentes, sendo a maioria expondo posicionamentos de que o programa não atendia às demandas da sociedade. 
Como exemplo de uma avaliação que demonstraria deficiências do programa em relação às necessidades da sociedade, expõe-se a colocação de um egresso que defendeu sua dissertação em 2010:

Respondente: O programa foi extremamente acadêmico e pouco voltado ao mercado. Hoje atuando em instituição com educação à distância sinto que a formação foi muito dimensionada para suprir um nicho específico (preenchimento de vagas em instituições de ensino superior de alto nível), negligenciando setores como a docência em cursos de formação profissional básica, uma necessidade atual do país. [Egresso 1]

Esse cenário pode ser interpretado como reflexo das ponderações na avaliação da CAPES em que inserção social representa apenas $10 \%$. Como contraponto, apresenta-se um exemplo de posicionamento de aluno que defendeu sua dissertação em 2008, e afirma que o programa atende às demandas da sociedade:

Respondente: Os docentes do programa têm a preocupação de atualizar-se frente aos acontecimentos ocorridos atualmente. [Egresso 2]

No segundo grupo de questões, solicitou-se aos egressos a indicação de notas de 1 a 10 para avaliações do programa. Observa-se, pela figura 1, que as piores avaliações foram para quesitos que envolvem aspectos financeiros do programa (Financiamento para eventos e publicações - 5,4 e Disponibilidade de bolsas - 6,6).

As avaliações com segundo menor grupo de notas referem-se a aspectos de conteúdo do programa: qualidade das disciplinas $(7,7)$ e conteúdo da grade curricular $(7,7)$, os apontando como possíveis barreiras, corroborando com o estudo de Lima, Vendramin e Casa Nova (2017). Cabe ressaltar que a média das notas foi alta, e observa-se um baixo índice de insatisfação, visto que houve poucas notas menores ou iguais a 5. As melhores avaliações ficaram para a qualidade da orientação $(8,6)$ e infraestrutura $(8,9)$.

Figura 1 - Resumo das notas dadas às características do programa pelos egressos

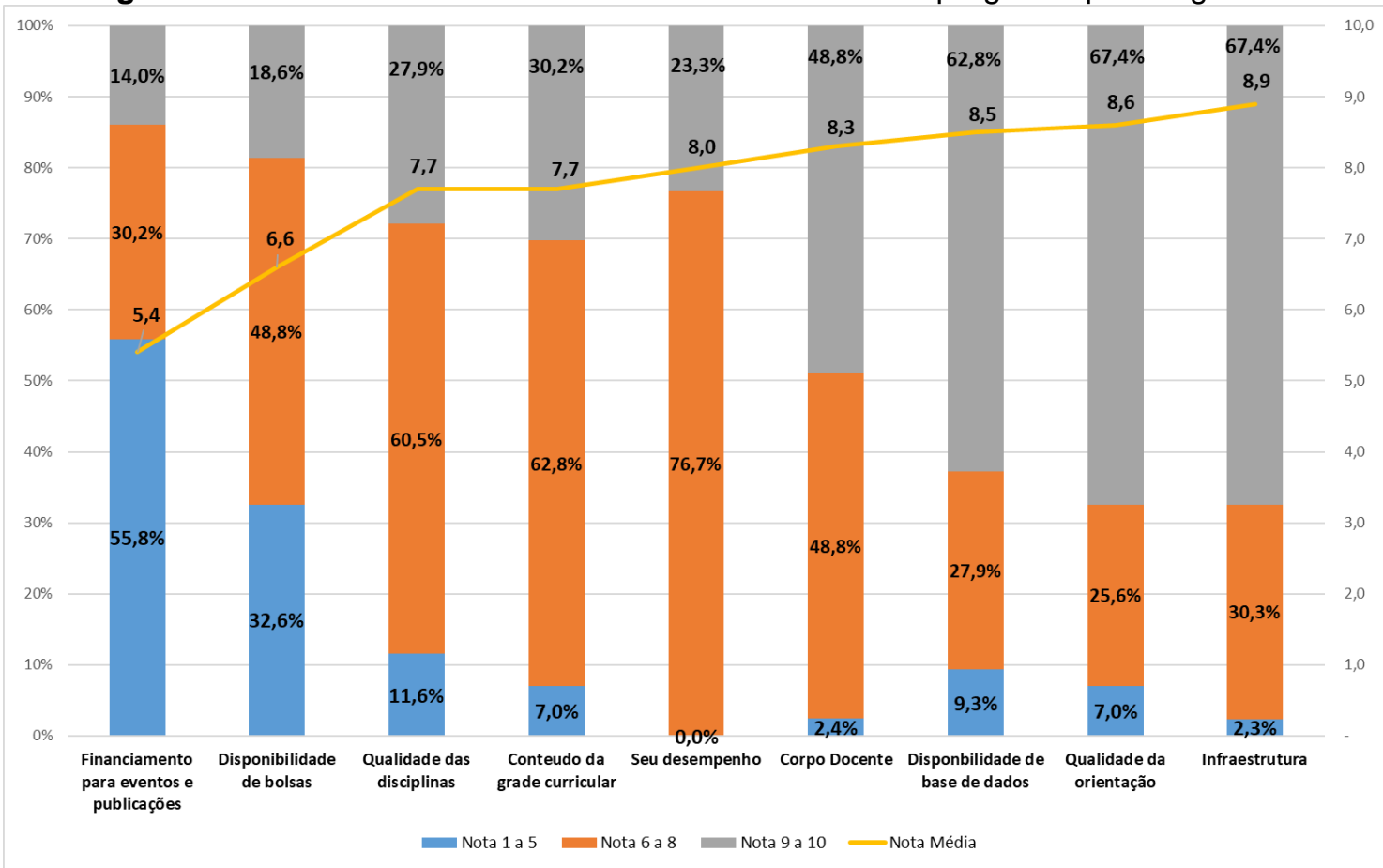

Fonte: Elaboração própria com dados da pesquisa

Ao se analisarem as notas dadas ao programa em função do período de conclusão em apenas um ponto, ocorreu diferença significativa de avaliação pelo teste de Mann-Whitney, o qual visa comparar duas amostras independentes e não pressupõe normalidade dos dados. Dessa forma, é considerado um teste estatístico não paramétrico (NACHAR, 2008). Já no caso do teste Qui-Quadrado, também considerado um teste estatístico não paramétrico, avaliam-se respostas não numéricas (SHARPE, 2015) Na avaliação do corpo docente, observou-se que os alunos concluintes do período de 2006 a 2010 indicaram média 8,8, e os concluintes de 2011 a 2014 indicaram nota média 8,0. 
O estudo de Quintal et al. (2012) também realizou avaliações gerais do programa, porém utilizou uma escala de 5 pontos. Fazendo uma adaptação de conversão, para avaliação de comparação, observa-se que as notas de Infraestrutura e Corpo docente foram superiores neste estudo; já quanto ao currículo, a nota desta pesquisa foi próxima ao estudo de Quintal et al. (2012).

Ao se avaliar aqueles que deram continuidade ao mestrado, por meio de programas de doutoramento, observam-se duas diferenças significativas: na avaliação da qualidade das disciplinas e disponibilidade de bases de dados. Na primeira avaliação, os egressos que não iniciaram doutorado indicaram nota média 8,2, e os que iniciaram programas de doutorado foram mais críticos e indicaram notas médias 7,3. A diferença é mais crítica quando se analisa a segunda avaliação, visto que os que não iniciaram programa de mestrado deram nota média 9,1 , e os que iniciaram programas de doutorado deram nota média 7,9.

Assim, respondendo à proposta levantada pelo estudo, ou seja, sobre a análise da percepção do egresso do Programa de Pós-Graduação em Controladoria e Contabilidade da FEARP-USP a respeito do programa e sua experiência como pós-graduando, o estudo demonstrou que, de maneira geral, o programa mantinha carga elevada de disciplinas, possuía certa sobreposição de disciplinas e o processo avaliativo era adequado. Sobre a metodologia do ensino desenvolvida nas disciplinas, houve concordância pela maior parte dos egressos. Ainda sobre o programa, os alunos não identificaram a atuação dos grupos de pesquisas.

Com relação ao perfil social, acadêmico e profissional dos egressos, conclui-se que, em média, a renda mensal era de $R \$ 9.300,00$, que a maioria era perfil acadêmico com inserção na carreira docente e que mantiveram forte relacionamento com os seus respectivos orientadores.

\section{CONSIDERAÇÕES FINAIS}

Conforme exposto, o processo avaliativo é necessário para a evolução de programas de pósgraduação stricto sensu, visto que permite sua melhoria a partir de uma melhor compreensão de seus pontos críticos, bem como possibilita a reflexão sobre suas ações. Um destes instrumentos é a avaliação de seus egressos.

Neste sentido, a pesquisa desenvolvida trouxe alguns apontamentos interessantes, tanto da melhoria de indicadores como de sugestões de pontos para reflexão por parte da coordenação do programa objeto de análise - programa de contabilidade e controladoria da FEARP-USP. Com o objetivo inicial de analisar a percepção do egresso sobre o programa mencionado, os achados em destaque foram:

I.melhoria nos indicadores de publicação, principalmente do quesito de publicação dos resultados das dissertações;

Il.volume de egressos que atuam em atividade acadêmica profissional indica a importância da preparação para a formação docente, e esta atividade já se iniciou no programa, portanto pode ser um importante indicativo de continuidade;

III.aspectos financeiros, como bolsas e apoio para publicações e eventos, são situações exógenas ao programa, em função de repasses públicos, entretanto reforça a discussão de busca de recursos alternativos para o programa;

IV.necessidade de expansão de ações de internacionalização, que pode ser efetuada, não somente com o envio de alunos para o exterior, mas também com atividades de pesquisa com grupos de pesquisa internacionais e vinda de docentes convidados;

V.medidas para viabilizar a inserção dos egressos em grupos de estudos e pesquisas;

VI.baixa relação da academia e mercado presente neste estudo já foi detectada em nível de graduação na mesma unidade, conforme demonstraram Miranda, Pazello e Lima (2015), o que demanda melhor compreensão desta demanda.

Como propostas de trabalhos futuros, sugerem-se pesquisas comparativas com os outros programas, tanto da unidade como de outras Instituições. Tal comparação pode trazer discussões acerca de diferenças de formação do perfil profissiográfico, avaliação dos programas e padrão de publicações, entre outros fatores. Sugere-se, ainda, a avaliação qualitativa da experiência desses egressos por meio de trabalhos qualitativos que possam trazer novos insighs não considerados no modelo apresentado. Outra sugestão para pesquisas futuras é o aprofundamento dos estudos sobre as iniciativas de formação docente que os programas têm proporcionado para seus alunos. Também pode ser ressaltado o aprofundamento para a análise do baixo relacionamento academia e mercado, a partir de uma avaliação da percepção dos docentes. 


\section{REFERÊNCIAS}

BARTH, T. G. et al. Mestrado em contabilidade: uma investigação do perfil de pesquisador dos egressos. Registro Contábil, v. 3, n. 2, p. 18-37, 2012.

BERNDT, A. A questão da orientação na pós-graduação em Administração. 2003. Disponível em: <http://www.forvm.org.br/educarnav.html>. Acesso em: 13 de nov. de 2016.

BEUREN, I. M. Como elaborar trabalhos monográficos em contabilidade. São Paulo: Atlas, 2006.

CAMPOS, V. T. B.; BORGES, M. F.; ARAUJO, J. B. Programa de Acompanhamento e Avaliação da CAPES: Qualidade Acadêmica ou Controle do Estado. Revista Educação e Políticas em Debate, v. 3, n. 1, p. 193-210, 2014.

COORDENAÇÃO DE APERFEIÇOAMENTO DE PESSOAL DE NÍVEL SUPERIOR. Cursos Recomendados/Reconhecidos. Brasília: CAPES, 2016. Disponível em: <http://www.capes.gov.br/cursosrecomendados $>$. Acesso em: 13 de nov. de 2017.

CUNHA, J. V. A.; CORNACHIONE JUNIOR, E. B.; MARTINS, G. A. Doutores em Ciências Contábeis: Análise sob a Óptica da Teoria do Capital Humano. Revista de Administração Contemporânea, v. 14, n. 3, p. 532-557, 2010.

DILLMAN, D. A. Mail and Internet surveys. New York: John Wiley \& Sons, 2000.

ERDMANN, A. L.; FERNANDES, J. D.; TEIXEIRA, G. A. (2011). Panorama da educação em enfermagem no Brasil: graduação e pós-graduação. Enfermagem em foco, v. 2 (supl.), p. 89-93, 2011.

GIULIANI, A.C. Perfil Profissiográfico dos Egressos do Programa de Mestrado Profissional em Administração de uma Instituição de Ensino do Interior do Estado de São Paulo. Revista de Administração da UFSM, v. 3, n. 1, p. 94-108, 2010.

GUIMARÃES, I. P.; SLOMSKI, V. G.; GOMES, S. M. S. Gestão do projeto político-pedagógico do cursos de ciências contábeis e o currículo como instrumento de sua concretização. Revista de Contabilidade da UFBA, v. 4, n. 1, p. 3655, 2010.

LIMA, J. P. R.; VENDRAMIN, E. O.; CASA NOVA, S. P. C. Identidades acadêmicas em uma era de Produtivismo: o (des)alojamento das mulheres contadoras. In: SEMINÁRIOS EM ADMINISTRAÇÃO, 20., 2017. São Paulo. Anais..., São Paulo: Faculdade de Economia, Administração e Contabilidade da Universidade de São Paulo, 2017.

LIMA, J. P. R. et al. "Ensina-me a orientar": o papel da relação de orientação na construção do ser orientador. In: SEMINÁRIOS DE ADMINISTRAÇÃO, 20., 2017, São Paulo. Anais... São Paulo: FEA/USP, 2017, 17p.

LIMA, F. C. D. et al. O choque com a realidade: dormi contador e acordei professor... Revista lberoamericana sobre Calidad, Eficacia y Cambio en Educación, v. 13, n. 1, p. 49-67, 2015.

LINS, M. P. E.; ALMEIDA, B.; BARTHOLO JUNIOR, R. S. Avaliação de desempenho na pós-graduação utilizando a análise envoltória de dados: o caso da Engenharia de Produção. Revista Brasileira de Pós-Graduação, v. 1, n. 1, p. 41-56, 2004.

MARTINS, O. S.; MONTE, P. A. Mestres em Ciências Contábeis: Uma Análise Sob a Ótica da Teoria do Capital Humano. Revista de Educação e Pesquisa em Contabilidade, v. 3, p. 1-22, 2009.

MARTINS, O. S.; MONTE, P. A. Variáveis que explicam os desempenhos acadêmico e profissional dos mestres em contabilidade do programa multi-institucional UNB/UFPB/UFRN. Revista Universo Contábil, v. 7, n. 1, p. 68-87, 2011.

MIRANDA, C. M. G.; ALMEIDA, A. T. Visão multicritério da avaliação de programas de pós-graduação pela capes: o caso da engenharia III baseado nos métodos Electre II e Maut. Gestão \& Produção, v. 11, n. 1, p. 51-64, 2004.

MIRANDA, C. S.; PAZELLO, E. T.; LIMA, C. B. Egressos como instrumento de avaliação institucional: uma análise da formação e empregabilidade dos egressos da FEA-RP/USP. Revista Gestão Universitária na América Latina GUAL, v. 8, p. 298-321, 2015.

MOREIRA, A. F. A cultura da performatividade e a avaliação da pós-graduação em educação no Brasil. Educação em Revista, v. 25, n. 3, p. 23-42, 2009.

MOREIRA, C. O. F.; HORTALE, V. A.; HARTZ, Z. A. Avaliação da pós-graduação: buscando consenso. Revista Brasileira de Pós-Graduação, v. 1, n. 1, p. 26-40, 2004.

NACHAR, Nadim et al. The Mann-Whitney U: A test for assessing whether two independent samples come from the same distribution. Tutorials in quantitative Methods for Psychology, v. 4, n. 1, p. 13-20, 2008.

PAIXÃO, R. B.; HASTENREITER FILHO, H. N. Autoavaliação de impactos: o que nos dizem os egressos de um mestrado profissional em administração? Administração: Ensino e Pesquisa, v. 15, n. 4, p. 831-859, 2014.

PELEIAS, I. R. et al. Evolução do ensino da contabilidade no Brasil: Uma análise Histórica. Revista de Contabilidade \& Finanças, v. 18, p. 19-32, 2007.

QUINTAL, R. S. ET AL. Perfil e percepções dos egressos do programa de mestrado em Ciências Contábeis de uma universidade estadual brasileira. Administração de Empresas em Revista, v. 11, n. 12, p. 130-148, 2012.

RIBEIRO, Marinalva Lopes. A afetividade na relação educativa. Estudos de psicologia, v. 27, n. 3, p. 403-412, 2010.

SANTOS FILHO, J. C.; CARVALHO, M. L. R. D. Orientação coletiva de mestrado na Faculdade de Educação da UNICAMP. Caderno de Pesquisas, n. 78, p. 73-79, 1991. 
SHARPE, Donald. Your chi-square test is statistically significant: now what?. Practical Assessment, Research \& Evaluation, v. 20, 2015.

SOARES, S. V.; NOVA, S. P. C. C. A avaliação de programas da CAPES, os conceitos e o uso de indicadores bibliográficos. Revista Gestão Universitária na América Latina - GUAL, v. 8, n. 2, p. 278-301, 2015.

SOUZA, M. A. Avaliação de egressos de cursos de pós-graduação stricto sensu em administração da Universidade Federal da Bahia. 2014. 128 f. Dissertação (Mestrado em Administração) - Escola de Administração, Universidade Federal da Bahia, Salvador, 2014.

TEIXEIRA, D. J.; OLIVEIRA, C. C. G.; FARIA, M. A. Perfil dos egressos do programa de mestrado profissional em administração da PUC Minas/FDC no período de 2000 a 2005. Revista Economia \& Gestão, v. 8, n. 16, p. 100-118, 2008.

VEndRAmin, E. O.; ARAUjo, A. M. P. Análise descritiva da Área de Pesquisa em Ensino Contábil no Brasil. In: CONGRESSO ANPCONT, 8., 2014. Rio de Janeiro. Anais... Rio de Janeiro: ANPCONT, 2014.

VIOTTI, E. B. et al. Programas de Mestrado e Doutorado. In: CENTRO DE GESTÃO E ESTUDOS ESTRATÉGICOS (Org.). Mestres e Doutores 2015: estudos da demografia da base técnico-científica brasileira. Brasília: Distrito Federal, 2016. p. 21-58. 
